\title{
No Homo: Gendered Dimensions of Homophobic Epithets Online
}

\author{
C. J. Pascoe, 1 四
}

Emailcpascoe@uoregon.edu

Sarah Diefendorf, 2

1 Department of Sociology, 1291 University of Oregon, Eugene, OR, 97405 USA

2 Department of Sociology, University of Washington, Seattle, WA, USA

\section{Abstract}

We examine a case of homophobic language online, specifically the deployment of the phrase "no homo," shorthand for "I'm not a homosexual." An analysis of 396 instances (comprising 1061 individual tweets) of the use of the phrase "no homo" on the social media platform Twitter suggests that the phrase is a gendered epithet that conveys cultural norms about masculinity. The first finding is that the phrase is used more often by male tweeters than by female tweeters. The second, as predicted by the literature on homophobia, is that the phrase is used in a negative emotional context to convey disapproval for men's homosexuality or behavior that is not gender normative. The third finding is that the modal use of the phrase "no homo" is in a positive emotional context, accompanying expressions of men's pleasure, desire, affection, attachment, and friendship. Our analysis suggests that the phrase "no homo" is a gendered one, primarily used by men to facilitate a particularly masculinized construction of positive emotional expression. Our research adds to and complicates findings on the relationship between homophobia and masculinity that suggests that homophobia is an organizing principal of masculinity in western cultures.

\section{Keywords}

Homophobia

Emotion

Men

Masculinity 
Scholars have long suggested that homophobia is central to a masculine identity in western cultures (Connell 2005 1995). However, by many measures, levels of homophobia expressed by both men and women have been declining in the United States. For instance, expressions of homophobia among North American college students have declined relatively steadily since the 1970s (Altemeyer 2001; Lance 2008). Similarly a recent Pew study finds that support for gay marriage has reached an unprecedented level of 55\% of Americans (Pew Research Center 2016). This is a dramatic and rapid rise from Pew's 2003 survey that indicated a level of support of $32 \%$ (Pew Research Center 2003). Men still approve of gay marriage at lower rates than women do, as well as older people at lower rates than younger people. But between 2003 and 2013, men between the ages of 18-49 changed the most in their approval of gay marriage, increasing their approval by 18 percentage points. AQ1

These changes in opinions about same-sex marriage and homosexuality in general are part of a larger cultural shift in terms of gender and sexual norms, especially among young men (Bridges and Pascoe 2014). This shift necessitates a return to early theorizing of the relationship between homophobia and masculinity in which scholars suggested that homophobia was "a central organizing principal of our cultural definition of manhood" (Kimmel 1994, p. 277). We propose that analyzing the meanings contained in homophobic language can help us understand the contemporary relationship between masculinity and homophobia, given these recent cultural shifts. As such, in our research project we ask: "What meaning is produced when people make homophobic comments?" Specifically we address the use of the epithet, "no homo," on the microblogging website, Twitter. A content analysis of 396 instances (comprising 1061 individual tweets) of the phrase "no homo" on the social media platform Twitter suggests that this homophobic phrase is deployed as a form of gendered norm enforcement, reflecting current cultural expectations of masculinity.

In line with previous research on homophobic epithets, we suggest that the deployment of the phrase "no homo" is a gendered practice that works to define parameters of normative masculinity. Three main findings emerged from this analysis. First, the phrase is a gendered one, used primarily by men. Second, as predicted by the literature on homophobia, the phrase "no homo" is used in a negative context to convey disapproval for men's homosexuality (Connell 2005) or gender transgressive behavior (Kimmel 1994; Pascoe 2011). The third finding is 
that the modal use of the phrase "no homo" is in a positive emotional context, accompanying expressions of men's pleasure, desire, affection, attachment, and friendship. Based on these findings we argue that the phrase "no homo" is deployed to facilitate a masculinized construction of positive emotional expression.

These findings indicate that the gender norm enforcement conveyed by "no homo" is a more complex deployment of homophobic language than has been revealed by previous research, which suggests that homophobic language is primarily negative. Our paper will address these contradictory processes and conclude by suggesting a return to the call issued years ago by Bryant and Vidal-Ortiz (2008) that we need to re-theorize homophobia. That is, by acknowledging that homophobia may reflect (and accomplish) different forms of social work-the reproduction of structural inequalities, psychological revulsion, and enforcement of social norms - we need to theorize multiple forms of homophobia itself because a singular concept may obscure multiple social processes at play.

\section{Gendered Homophobia}

Qualitative sociological research documents the gendered nature of homophobia in contemporary western cultures. According to this line of research, homophobic epithets are not only about a dislike of gay people, but also are a form of gender regulation. Homophobia and homophobic language are central to shaping contemporary heterosexual masculine identities (Kehler 2007; Levy et al. 2012; Pascoe 2011; Poteat et al. 2011; Thorne and Luria 1986). Indeed, scholars of masculinity have pointed out that homophobia is a significant component in how boys come to think of themselves as men (Kehily and Nayak 1997; Kimmel 1994; Lehne 1998; Pascoe 2011; Schrock and Schwalbe 2009).

Young men's homophobic practices often take the form of a "fag discourse" (Pascoe 2003) consisting of jokes, taunts, imitations, and threats through which boys publicly signal their rejection of that which is considered unmasculine. In other words, homophobic harassment has as much to do with definitions of masculinity as it does with an actual fear of other gay men (Corbett 2001; Kimmel 1994). These insults are levied against boys who are not masculine, if only momentarily, and boys who identify (or are identified by others) as gay. Interactions like this set up a very complicated daily ordeal in which boys continually strive to avoid being subject to homophobic epithets, but are simultaneously constantly vulnerable to them, whether or not they actually identify as gay (Kimmel and Mahler 2003; Pascoe 2011). Boys use these epithets more than girls do and rate them much more seriously (Thurlow 2001). According to this line of research, homophobic bullying 
is a part of boys' gender socialization into normatively masculine behaviors, practices, attitudes, and dispositions (Corbett 2001; Kimmel 1994; Pascoe 2011).

Some homophobic epithets appear to be gender-neutral, such as the phrases "that's gay" and "no homo." "That's gay" is used ubiquitously as an insult for anything that is stupid (Pascoe 2011). The expression "no homo" is shorthand for "I'm not a homosexual" and is perhaps a follow up to the use of "pause" which conveyed similar sentiment. It emerged out of hip hop culture in the 1990s to negate gender and sexual transgressions, but has disseminated through wider culture since then (Brown 2011). This phrase is often used when men are expressing affection toward one another, or acting in a way that could be deemed unmasculine or weak (Ikard 2013). As Ikard (2013) indicates this is a particularly masculine term. As Brown (2011) suggests, the term reveals an unease with sexual and gender nonconformity.

The little empirical research on the phrase suggests that it may function to carve out a space in which sentiments that may seem incongruous with a normatively masculineity self might be expressed. In analyzing Swedish rap lyrics from 1991 to 2011, Berggren (2012) suggests that the term functions as a "straight inoculation" to maintain heterosexuality while in an ambiguous situation, such as expressing closeness with another man. He argues that the term covers up fissures and contradictions revealed by the use of homoerotic metaphors in the lyrics. Niobe Way's (2012) work with male adolescents supports Berggren's interpretation. She argues, based on her interviews with male adolescents, that these young men want intimate close friendships but by late adolescence "boys become wary of their male best friends even as they continue to want emotional intimacy" (Way 2012, p. 116). Although these young men did not describe their friendships as gay, she describes "no homo" as a "verbal tick" (p. 126) deployed by male adolescents when talking intimately about their male friends. In an analysis that perhaps speaks to the complicated usage of the phrase by the young men in Way's research, Bryant and Vidal-Ortiz (2008, p. 388) suggest that "in many instances homophobia has become a taken-for-granted term that is often deployed without adequate critical attention to its meanings and consequent effects." The present research heeds that call by investigating the meanings conveyed by a specific homophobic epithet.

\section{Measuring Homophobias}

Although measurements of levels of homophobia in the United States have shown a definitive decline over the past 30 years (Pew Research Center 2016), this change is uneven and not always unidirectional (Plummer 2014). Attitudes toward the morality of same-sex relationships became more liberal from 1973 to 76 in the 
United States, and then more conservative through 1990 before beginning to liberalize again (Loftus 2001). During much of that time women's opinions changed more than men's (Altemeyer 2001). Men still espouse higher levels of homophobia toward gay men than toward lesbians, but men also represent the group with one of the most dramatic changes regarding views on gay marriage on recent surveys (Pew Research Center 2016). Some personality types, such as Right Wing Authoritarian personalities, remain more staunchly homophobic than others are (Altemeyer 1988; Lance 2008).

Recently, some countries have experienced rapid public increases in homophobia as measured by new laws against homosexuality (Plummer 2014), leading Plummer (2014) to suggest that homophobias may "ebb and flow." During these periods of ebb and flow, scholars debate whether or not homophobia remains a significant element of social life. We argue that it does, but suggest that perhaps part of the existence of this debate is due to variations in the measurement of homophobia and a failure to better refine and theorize homophobia as a concept.

A recent systematic review of the instruments used to measure homophobia reveal 47 different approaches between 1993 and 2010 (Costa et al. 2013). Such a varied understanding and approach to homophobia is especially important to recognize because different measures of homophobia reveal different levels of change. People, for instance, espoused different levels of support regarding the morality of same-sex relationships than support for the civil liberties for gays and lesbians (Loftus 2001). The willingness to restrict civil liberties more steadily declined than did views on morality (Loftus 2001). Similarly, a recent study found that whereas $70 \%$ of heterosexual respondents support inheritance rights for same-sex couples, only 55\% of that same sample approve of gay men kissing each other on the cheek in public (Doan et al. 2014). Perhaps not surprisingly, 72\% of heterosexual respondents approved of public displays of affection by lesbians (Doan et al. 2014). These disjunctures illustrate a need for a refined theorizing of a variety of homophobias, perhaps in a way that distinguishes the different sentiments embedded in approving of same-sex marriage while disapproving of physical affection.

To capture these different sentiments, scholars have framed homophobia in a variety of ways. Some have re-conceptualized homophobia as a sexual stigma (Herek 2007, 2015), as a multi-leveled typology (Herek 2004), or as something that should be understood through the lens of gender taboos (Plummer 2014). Herek, among others, argues that we need to distinguish between sexual prejudice and homophobia (Herek and McLemore 2013). Others call for an intersectional approach to 
homophobia (Meyer 2012), and many argue that homophobia should not be thought of as a psychological trait but rather as a social construct (McCann et al. 2010). Scholars now use a variety of terms to capture varieties of anti-same-sex sentiment, such as homonegativity (Mayfield 2001), heterosexism (Ezzell 2009; Sears and Williams 1997), homohysteria (McCormack and Anderson 2014), and effemiphobia (Roach 2015). These different framings of homophobia suggest that perhaps some specific forms of homophobia are declining, whereas others are not. Plummer rightly suggests that the meanings and rates of homophobia remain an "unsettled question"- if nothing else because the way we understand and employ it as a term does not reflect nor capture the meanings conveyed in homophobic epithets (Plummer 2014).

Large-scale studies on homophobia report declines in homophobia by certain measures, indicating evidence for different trends in homophobia. Qualitative research focuses on meanings conveyed in homophobic interactions. For instance, interview-based and ethnographic studies emphasize meanings of homophobia and report gendered-norm enforcement in their findings. This research covers a middle ground-combining the amount of data present in some survey-oriented studies with an emphasis on meaning often found in qualitative research focused on smaller populations.

\section{New Media}

Over the past decade and a half, homophobic insults quickly made the move from offline to online spaces in the shift from what many call traditional bullying to cyberbullying (Allison and Bussey 2016; Erdur-Baker 2010; Ey et al. 2015; Kowalski et al. 2014; Zych et al. 2015). Data on rates of cyberbullying compared to traditional bullying indicate a wide range of results. Whereas many find that rates of cyberbullying fluctuate depending on age (Kowalski et al. 2014), technology being used (Kowalski et al. 2014), gender (Erdur-Baker 2010), and a variety of personal and psychological traits (Zych et al. 2015), such as normative beliefs about aggression (Kowalski et al. 2014), poor measures for the phenomenon also yield inconsistent results (Zych et al. 2015). Although some suggest that the potential for anonymity in online spaces may distinguish cyberbullying from traditional bullying (Allison and Bussey 2016; Erdur-Baker 2010; Kowalski and Limber 2008;

Kowalski et al. 2014), cyberbullying does not appear to be more prevalent than traditional bullying. There is no reason to think that the online world is worse than the offline one. 
Research on cyberbullying is often located within the field of psychology, with a focus on the relationship between cyberbullying and self-harm, suicidal ideation, and negative emotions (Zych et al. 2015). Most of the work on this form of online aggression has focused on traits of the bully and victim. Some suggest that a "general aggression model" is most useful in understanding this phenomenon (Kowalski et al. 2014, p. 1110). Others argue that such individual approaches to cyberbullying miss larger sociological patterns, and they call for a sociological framing of cyberbullying (Ey et al. 2015). This sociological framing should focus more on particular meanings of aggressive talk in online spaces, acknowledge that it can and should be conceptualized as a group phenomenon (Allison and Bussey 2016), and particularly call attention to racist and homophobic cyberbullying (Zych et al. 2015). This subfield is fractured and under-theorized (Kowalski et al. 2014), and there is a consistent call for more research needed in this area (Erdur-Baker 2010). Our study of homophobic language online speaks to varied understandings of aggressive talk in online spaces, complicating what might seem, at first blush, as simple anti-gay prejudice.

\section{Method}

\section{Twitter}

The present study examines the use of the phrase "no homo" on the social media site Twitter. Twitter is a micro blogging service in which users can write statements of 140 characters or less and broadcast them out either publicly or to an audience of people they have allowed to follow them should they have a "private" account. Once a user has followed another user, then the following user sees all of the tweets of the user they have followed. Users may write back-and-forth to one another in tweet format (something that is viewable by all of their followers) or they may write direct messages to one another that are private. Users may also organize or tag their tweets with "hashtags," words or phrases preceded by a "\#” symbol. Users can search for tweets using a given hashtag if they are interested in a specific topic. Hashtags can serve as an organizing, literal function (such as tagging things pertaining to a given topic) or function as a sort of meta-commentary that reflects on the tweet itself.

Twitter has 330 million active monthly users, 100 million of whom use it daily (Omnicore 2018). Although 67 million of these users are located in the United States, $79 \%$ of Twitter accounts are located outside the United States (Omnicore 2018). Because of the presence of automated Twitter accounts (commonly called 
"bots"), as well as an inconsistent relationship between the number of tweets a particular account produces and a widely varying number of followers and "retweets" (or the sharing of a tweet written by someone else), it is difficult to paint a picture of the makeup of information found on Twitter, which may or may not reflect the demographics of its account base. In terms of users in the United States, the Pew Research Center's Internet and American Life Project describes the typical American Twitter user as an 18-29 year-old educated racial/ethnic minority with a well-paying job who is slightly more likely to be male than female. Twitter users are typically educated (39\% have at least some college experience) and hold a middle or upper-middle class job (42\% earn $\$ 50,000$ per annum or more) (Duggan 2015). Only 44\% of the tweet instances in the present study $(n=174)$ were issued from accounts based in the United States, Canada or western Europe; $2.5 \%(n=10)$ of the accounts tweeting "no homo" in our study were located outside these locations, and $53.5 \%(n=212)$ of the accounts tweeting the phrase "no homo" did not provide geographic information.

The present data are part of a larger project investigating the use of a variety of homophobic epithets on Twitter. The larger study examines 2,000 examples of phrases "dyke," "fag" or "faggot" and "no homo" used on Twitter between June and August of 2014. During July and August of 2014 we gathered 500 tweets containing each of the phrases on five different days as well as the conversation in which a given tweet was embedded, if applicable, and the information (location, race, gender) associated with the user's account that tweeted the phrase. Using the search function on Twitter yields only publicly available tweets, but fully $88 \%$ of tweets are publicly available (Loker 2012). Even though the tweets are publicly available, we have changed the names of the users as well as the occasional word in order to render both users and tweets more difficult to search.

\section{Sampling Strategy}

Fully 500 instances of the use of "no homo" were collected on Twitter during the study period. We define an instance as either a single tweet or a tweet embedded in a conversation that includes the phrase "no homo." For example, a single tweet that says "I love ice cream \#nohomo" would count as an instance and one tweet. A tweet that says "I love you bro" followed by a response tweet of "I love you too man \#nohomo" counts as one instance, but contains two tweets. We excluded 104 instances from our analysis because they were not in English, were duplicates of other tweets, or were missing enough context that we were not able to analyze them. Of the remaining 396 instances, 152 tweets were part of a larger conversations and 244 were stand-alone tweets. This lead to a total of 396 instances for analysis 
comprised of 1061 tweets. All percentages in our article refer to instances, not individual tweets.

\section{Coding Process}

The gender and race of the tweeters captured in these instances were determined, when possible, by both authors, using a combination of the user's Twitter handle, profile picture, Twitter bio, and content of the tweet (and conversation when applicable). This method does not take into account the self-identifications of the individuals in question, so the following percentages should be read as a reflection of the authors' assigned categories, not as the tweeters' self-definitions. In terms of race, $32.3 \%(n=128)$ of those tweeting "no homo" were White, $18.4 \%(n=73)$ Black, 6.1\% $(n=24)$ Latinx, 2.7\% $(n=11)$ Asian, and 40.4\% $(n=160)$ were determined unknown by the authors. This distribution compares to the overall racial breakdown of Twitter users: 59\% White Non-Hispanic, 18\% Black Non-Hispanic, $12 \%$ Hispanic, and $11 \%$ other or unknown (Koh 2014). The gender breakdown of Twitter users is difficult to assess (for a fuller explanation of why particular demographics of Twitter users are difficult to identify, please see Mislove et al. 2011). In terms of gender, $71.5 \%$ of the instances of "no homo" were tweeted by men, $21 \%$ by women, and $7.6 \%$ of those tweeting "no homo" were coded as unknown gender by the authors. According to Pew Research Center, 24\% of American men who are online use Twitter and 25\% of American women who are online use the service (Smith and Anderson 2018). American men and women go online in relatively equal proportions ( $89 \%$ and $88 \%$ respectively) (Anderson et al. 2018). As such these data suggest that they use Twitter in relatively equal numbers.

We divided all tweets by week collected, and then split them into two smaller datasets, grouping weeks 1 and 2 together and weeks 3, 4, and 5 together. The first author took the second dataset and second author took the first. Using a grounded theory approach (Charmaz 2014), each author conducted initial coding. In this process we discovered that the majority of tweets containing the phrase "no homo" were expressing a particular emotion. Based on this insight and the initial coding process, we developed a set of 13 focused codes and subcodes that were then used to recode the data with a focus on emotional expression. Each author coded a randomly selected sub-sample of 79 instances using the focused codes. The Krippendorf's alpha score for this shared sub-sample is .8013 .

Applying qualitative methods to digital data builds on the growing field of sentiment analysis in online environments. Most sentiment analysis, or opinion mining (Pang and Lee 2008), uses a computer program to characterize the 
emotional content, or the estimation of the emotion contained in the language of an individual tweet. For example, on March 13th, 2018 Sentiment Viz, an online sentiment analysis software, codes and positions $88.8 \%$ of the 310 tweets containing the phrase no homo that day as "pleasant." This same software generates a "tag cloud," or common words associated with the phrase, which indicates that words such as "love," "friend," "beautiful," "kiss," "bro," and "miss" are commonly associated with the phrase "no homo." However, sentiment analysis does not tell us why or how "no homo" is deployed in the expression of positive affect. This approach can miss the context, feelings, and meaning so crucial in understanding the use of an epithet such as "no homo." This ability to capture emotion in big data is a methodological puzzle (Lazer and Radford 2017).

To help solve this puzzle, we conducted our research in a spirit similar to that of sentiment analysis, with the goal of understanding the attitudes, emotion, and content of a tweet. We do this in three ways. First, we capture the larger conversation of which the tweet is a part, which allows us to analyze an interactional component that can be crucial to both producing and understanding emotion expressed in a tweet. Second, we are also able to see and code the emojis (a small image that helps to convey the emotional context of digital text) and pictures present in individual tweets and conversations that express emotion. Finally, unlike many "big data" approaches to tweets, we analyzed the profiles of individual tweeters to code their race and gender so that we could understand who was expressing a particular emotion. We are thus answering questions raised by big data by applying in-depth, qualitative methods to digital communication.

\section{Results}

An analysis of "no homo" on Twitter yields three main results, as evidenced by the three main codes and two additional major subcodes detailed in Table 1. The first finding is that its use is gendered; it is more likely to be used by and in conversation with (people who appear to be) men. The second finding is that "no homo" is used in a negative emotional context as a response to same-sex sexuality or to condemn insufficiently masculine behaviors, expressions or content. This however, was not the modal way it was used, accounting for only $11.9 \%(n=47)$ of the instances of "no homo" during the time period under study. The third finding is that "no homo" was most frequently used in expressions of positive emotions, accounting for $86.4 \%$ $(n=342)$ of the instances under study. These positive expressions took one of two forms: expressions about liking things, people, and practices or expressions of friendship in which tweeters wrote about spending time together or conveyed 
affection for friends. Tweets expressing positive emotions were evenly divided between these two codes.

\section{Table 1}

Coding of tweets, their definition, examples, and frequencies

\begin{tabular}{|c|c|c|c|}
\hline Code/subcode & Definition & Example & Frequency \\
\hline $\begin{array}{l}\text { Gender of } \\
\text { tweeter: man }\end{array}$ & $\begin{array}{l}\text { Based on the name, images } \\
\text { and information in the } \\
\text { tweet and in the tweeter's } \\
\text { profile, the tweeter is } \\
\text { coded as a man. }\end{array}$ & $\begin{array}{l}\text { Austin: call me gay, but I } \\
\text { would love to have one of } \\
\text { those slow lean in kisses at } \\
\text { the end of a date! \#nohomo } \\
\text { \#sensitive guy }\end{array}$ & $n=283$ \\
\hline $\begin{array}{l}\text { Gender of } \\
\text { tweeter: } \\
\text { woman }\end{array}$ & $\begin{array}{l}\text { Based on the name, images } \\
\text { and information in the } \\
\text { tweet and in the tweeter's } \\
\text { profile, the tweeter is } \\
\text { coded as a woman. }\end{array}$ & $\begin{array}{l}\text { Abigail: why is selena } \\
\text { gomez so perfect like why is } \\
\text { she so amazing I love her so } \\
\text { much \#nohomo }\end{array}$ & $n=83$ \\
\hline $\begin{array}{l}\text { Gender of } \\
\text { tweeter: } \\
\text { unknown }\end{array}$ & $\begin{array}{l}\text { Based on the name, images } \\
\text { and information in the } \\
\text { tweet and in the tweeter's } \\
\text { profile, the tweeter's } \\
\text { gender is coded as } \\
\text { unknown. }\end{array}$ & XYZ123: j/k nohomo & $n=30$ \\
\hline $\begin{array}{l}\text { Negative } \\
\text { emotional } \\
\text { usage }\end{array}$ & $\begin{array}{l}\text { The phrase no homo is } \\
\text { used in conjunction with } \\
\text { negative emotional } \\
\text { content. }\end{array}$ & $\begin{array}{l}\text { Kat: you and shake some } \\
\text { punks. Omg y'all weak lol. } \\
\text { Light guy: don't talk about } \\
\text { dido like that Kat I'll punch } \\
\text { yo ass \#nohomo }\end{array}$ & $\begin{array}{l}n=47 \\
(11.9 \% \text { of } \\
\text { all tweet } \\
\text { instances })\end{array}$ \\
\hline $\begin{array}{l}\text { Neutral } \\
\text { emotional } \\
\text { usage }\end{array}$ & $\begin{array}{l}\text { The phrase no homo is } \\
\text { used in conjunction with } \\
\text { an expression of a neutral } \\
\text { sentiment. }\end{array}$ & Jane: jk \#nohomo & $\begin{array}{l}n=7 \\
(1.8 \% \text { of } \\
\text { all tweet } \\
\text { instances })\end{array}$ \\
\hline $\begin{array}{l}\text { Positive } \\
\text { emotional } \\
\text { usage overall }\end{array}$ & $\begin{array}{l}\text { The phrase no homo is } \\
\text { used in conjunction with } \\
\text { an expression of a positive } \\
\text { sentiment. }\end{array}$ & $\begin{array}{l}\text { Don: the fact that people in } \\
\text { Chicago are } \\
\text { chanting ehanging "We have } \\
\text { real fans" makes me smile } \\
\text { \#nohomo }\end{array}$ & $\begin{array}{l}n=342 \\
(86.4 \% \text { of } \\
\text { all tweet } \\
\text { instances })\end{array}$ \\
\hline $\begin{array}{l}\text { Positive } \\
\text { emotional } \\
\text { usage - liking } \\
\text { things }\end{array}$ & $\begin{array}{l}\text { The phrase no homo is } \\
\text { used in conjunction with } \\
\text { an expression of liking } \\
\text { something. }\end{array}$ & $\begin{array}{l}\text { John: that chipotle thing tho, } \\
\text { dopest experience, made my } \\
\text { heart melt it even beat going } \\
\text { to the NYC one (tooth filled } \\
\text { emoji smile) \#nohomo }\end{array}$ & $\begin{array}{l}n=152 \\
(44.4 \% \text { of } \\
\text { all } \\
\text { instances } \\
\text { of positive } \\
\text { emotional } \\
\text { usage) }\end{array}$ \\
\hline
\end{tabular}




\begin{tabular}{|c|c|c|c|}
\hline Code/subcode & Definition & Example & Frequency \\
\hline $\begin{array}{l}\text { Positive } \\
\text { emotional } \\
\text { usage - liking } \\
\text { things: } \\
\text { compliments }\end{array}$ & $\begin{array}{l}\text { The phrase no homo is } \\
\text { used in conjunction with a } \\
\text { compliment directed at } \\
\text { someone else. }\end{array}$ & $\begin{array}{l}\text { Cole: s/o Daniel for always } \\
\text { having perfect hair } \\
\text { \#nohomo. }\end{array}$ & $\begin{array}{l}n=72 \\
(47.4 \% \text { of } \\
\text { all } \\
\text { instances } \\
\text { of liking } \\
\text { things) }\end{array}$ \\
\hline $\begin{array}{l}\text { Positive } \\
\text { emotional } \\
\text { usage - liking } \\
\text { things: } \\
\text { celebrities }\end{array}$ & $\begin{array}{l}\text { The phrase no homo is } \\
\text { used in conjunction with } \\
\text { an expression of liking or } \\
\text { appreciating a celebrity. }\end{array}$ & $\begin{array}{l}\text { Mark: I want that Colton } \\
\text { Hayes look. His style is } \\
\text { always on point. \#nohomo }\end{array}$ & $\begin{array}{l}n=47 \\
(30.1 \% \text { of } \\
\text { all } \\
\text { instances } \\
\text { of liking } \\
\text { things })\end{array}$ \\
\hline $\begin{array}{l}\text { Positive } \\
\text { emotional } \\
\text { usage - liking } \\
\text { things: sports }\end{array}$ & $\begin{array}{l}\text { The phrase no homo is } \\
\text { used in conjunction with } \\
\text { an expression of liking a } \\
\text { sport, an athlete or a team. }\end{array}$ & $\begin{array}{l}\text { Sean: the bulls. I do! I love } \\
\text { Dwade. \#NoHomo }\end{array}$ & $\begin{array}{l}n=27 \\
(17.8 \% \text { of } \\
\text { all } \\
\text { instances } \\
\text { of liking } \\
\text { things) }\end{array}$ \\
\hline $\begin{array}{l}\text { Positive } \\
\text { emotional } \\
\text { usage - } \\
\text { friendship }\end{array}$ & $\begin{array}{l}\text { The phrase no homo is } \\
\text { used in conjunction with } \\
\text { an expression of } \\
\text { friendship. }\end{array}$ & $\begin{array}{l}\text { Kyle: }<3 \text { back \#nohomo } \\
\text { \#bromance }\end{array}$ & $\begin{array}{l}n=168 \\
(49.1 \% \text { of } \\
\text { all } \\
\text { instances } \\
\text { of positive } \\
\text { emotional } \\
\text { usage) }\end{array}$ \\
\hline $\begin{array}{l}\text { Positive } \\
\text { emotional } \\
\text { usage - } \\
\text { friendship: } \\
\text { everyday } \\
\text { work }\end{array}$ & $\begin{array}{l}\text { The phrase no homo is } \\
\text { used in conjunction with } \\
\text { an expression of } \\
\text { friendship, specifically } \\
\text { about the daily nature of } \\
\text { the relationship. }\end{array}$ & $\begin{array}{l}\text { Brian: thinking we may need } \\
\text { a group shot in the bathhouse } \\
\text { \#NoHomo }\end{array}$ & $\begin{array}{l}n=58 \\
(34.5 \% \text { of } \\
\text { all } \\
\text { instances } \\
\text { of } \\
\text { friendship) }\end{array}$ \\
\hline $\begin{array}{l}\text { Positive } \\
\text { emotional } \\
\text { usage - } \\
\text { friendship: } \\
\text { deep affection }\end{array}$ & $\begin{array}{l}\text { The phrase no homo is } \\
\text { used in conjunction with } \\
\text { an expression of friendship } \\
\text { in terms of missing, caring } \\
\text { about or loving someone. }\end{array}$ & $\begin{array}{l}\text { Adam: @kevin ur still \#1 in } \\
\text { my heart \#nohomo }\end{array}$ & $\begin{array}{l}n=110 \\
(65.5 \% \text { of } \\
\text { all } \\
\text { instances } \\
\text { of } \\
\text { friendship })\end{array}$ \\
\hline
\end{tabular}

\section{Gendered Usage}

Consistent with other literature on homophobic epithets, the use of "no homo" is used primarily by men and in conversations between men. Fully $71.5 \%(n=283)$ of the instances of "no homo" were tweeted by men, $21 \%(n=83)$ by women, and $7.6 \%(n=30)$ of those tweeting "no homo" were coded as unknown gender by the authors. When "no homo" was clearly directed at someone else, 75\% $(n=196)$ of the time it was directed by a man to another man. $4.2 \%(n=11)$ of the time, "no 
homo" was directed by a man to a woman. $18 \%(n=47)$ of the time, "no homo" was directed by a woman to another woman, and $2.7 \%(n=7)$ of the time "no homo" was directed by a woman to a man. In terms of conversations between tweeters, $54.6 \%(n=83)$ of the conversations that included the epithet "no homo" were conversations between men, $18.4 \%(n=28)$ were conversations that involved both men and women, $13.2 \%(n=20)$ of conversations were between women only, and $13.8 \%(n=21)$ of these conversations were coded as of unknown gender composition.

In sum, the phrase "no homo" is more likely to be tweeted by men and to be used in a conversation between men on Twitter. Information about the gender of Twitter users suggest that men and women use Twitter at relatively equal rates and that, except in a small number of countries, worldwide men are more active users of Twitter (Jain and Nielsen 2016). Additionally, at least in terms of hashtag use, men are more likely to use Twitter for instrumental expression and women for emotional expression (Shapp 2015). As such gendered differences in use of "no homo" are likely not a result of who is using the social media platform.

\section{Negative Emotional Usage}

The literature on homophobia would suggest that homophobic epithets on Twitter would be used in a negative context - to insult others for identifying as gay, engaging in gender transgression or acting in a way indicative of having same-sex desire. Although we did see this disparagement in usages of "no homo," deployment of the phrase in a negative context only accounted for $11.9 \%$ of the instances in our study. When used in conjunction with a negative sentiment, "no homo" typically accompanies tweet content addressing gay identity, same-sex desire or same-sex sexual behavior.

When used negatively the phrase "no homo" can be deployed to mitigate against homosexuality. It can be used simply to indicate that one is literally not gay, as in this tweet by Kyle: "\#nohomo \#straight \#nothomo \#notgay." Kyle's tweet contains a series of hashtags about sexual identity_ "not gay" and "straight," for instance. It seems that this tweet is a quite literal pronouncement about sexual identity in which "no homo" serves to indicate an identification with heterosexuality.

Other tweets included the phrase alongside a mention a gay identity, when said identity was the subject of a tweet or series of tweets, as in the following conversation among tweeters Maggie, Dusty, and Kevin regarding the hip hop artist, Nas: 
Maggie: Nas is like my gay best friend but he's not gay (followed by three crying and laughing emojis). Dusty: INCORRECT. He Gay AF. Kevin: This nigga said im fine af. Dusty: I said NOHOMO, so this cant be used against me...you said Matt had a fat cock [penis]. Kevin: You lying.

When these three tweet about a celebrity (Nas) who may or may not be gay, Dusty asserts that because he used the phrase "no homo," the fact that he stated that Nas is "gay AF" (or "as fuck," meaning very or to a great extent) cannot be indicative of his own sexuality.

"No homo" is also deployed in a negative context when tweeters address another's gender transgression. In one series of tweets, tweeters respond to someone who has posted an image (presumably of herself) featuring a tall African-American woman lying down on her back, wearing a sports-bra and "boy briefs," heavy eyeliner, and long black hair with the text "I bless god for my chest." Two different tweeters retweeted the image with the following responses:

Frank: Take that fucking wig off, bro \#nohomo

Bob: nice one bruh, \#NoHomo

The comments by these tweeters question the gender identity of the original poster, asserting that while she appears to be a woman, she is actually a man. Both address their tweets to "bro" or "bruh," shorthand for "brother," accompanied by the hashtag "nohomo." When used in a negative emotional context, "no homo" accompanies tweets about gay identities, same-sex sexuality, and gender transgression.

\section{Positive Emotional Usage}

The main story told by the analysis of "no homo" on Twitter, however, is not one about explicit homophobia or the expression of negative sentiments. The most common use of the phrase "no homo" $(n=342)$ is in a positive emotional context. Fully $86.4 \%$ of the instances in our study contained the phrase "no homo" expressed alongside a positive sentiment. This positive emotional content takes two main forms: through expressions of "liking things" $(n=152 ; 44.4 \%$ of all instances of Positive Emotional Usage) and through expressions of friendship ( $n=168 ; 49.1 \%$ of all instances of Positive Emotional Usage). 


\section{Liking Things}

About half of the tweet instances $(n=152 ; 44.4 \%$ of all instances of Positive Emotional Usage) contain positive expressions of "liking things." In general, "no homo" can accompany liking a wide variety of things or phenomena, such as music, movies or doing a particular activity, as in the following individual instances:

Music:

Nathan: I may or may have "Let it Go" [a song from an animated Disney princess movie] on my iPhone.... \#NoHomo \#SeriouslyNoHomo (with blushing face emoji).

Mike: Low key [no big deal] I really like the song Boom Clap [a top 40 pop song] \#nohomo.

Movies:

Jake: The proposal [a romantic movie] is such a great movie (with aok sign emoji) \#nohomo.

Jeff: The Day After Tomorrow [a high-energy action movie] is still a tight [good] movie \#nohomo.

Ricky: the notebook [a romantic movie] \#nohomo.

Doing things:

R.J.: I would love to kill [eat] a dozen Krispy Kreme donuts and cry while watching a terribly sad movie tonight.

Joey: Nohomo that singing in the shower [a top 40 pop song] song get me hype.

Chris: My daily medication lately has been driving backroads into the sunsets \#relaxed \#FeelingFine. Sri: The route from dav thru Maysville and around Dixon [town names] is the best. Chris: yea I take Utica all the way out to the roads that lead up that way because the sunsets to the north \#NoHomo.

Lyle: I could just go for a movie, a girl to cuddle with and a cup of hot black raspberry tea rn [right now] \#nohomo 
\#justspeakingmycurrentfeelings.

Posters expressed favorable sentiments for a wide range of items-movies, food, sunsets, and music. Some of these expressions center on entertainment that is seemingly unmasculine: an anthem from a princess musical or a romantic comedy for instance. Others, however, appear acceptably masculine, such as the action movie The Day After Tomorrow. Others appear to be gender-neutral, such as driving and watching sunsets.

It seems, as in the examples that follow, that the actual gendered nature of what is being "liked" by the tweeter, does not necessarily matter when it comes to the use of the phrase, "no homo." For example, more specific forms of "liking things" include tweets that contain content about complimenting others, liking specific sports or liking celebrities.

Compliments Compliments ( $n=72 ; 47.4 \%$ of all instances of liking things) are a particular form of "liking things" that tweeters contextualize using "no homo." These compliments often involve one man commenting on another man's appearance.

Ty: (in response to a picture one of his friends shares that is a blackand-white photo of his muscular chest and abs) you're too sexy for life bro \#nohomo \#onlybromo (two smiling emoticons with heart eyes).

Mario: Bart has to be the best looking guy on earth. \#nohomo. Ergo: Nice new pic handsome. Lawrence: *blushes* Jay: Get a room! Lawrence: Haha \#nohomo.

Both of these instances involve male tweeters complimenting other tweeters, sharing some sexual content such as "too sexy for life" or "get a room," and then containing that sexual content with the use of the phrase, "no homo." Notably, many of these tweets are homosocial in nature, when one male tweeter compliments another man's appearance.

Celebrities Some tweeters use "no homo" in tweets that express admiration for a variety of celebrities, such as artists, singers, and actors $(n=47 ; 30.1 \%$ of all instances of Liking Things). These celebrities are usually the same gender as the tweeter (to the extent that the gender of the tweeter could be determined). 
Lance: I wouldn't mind if I had a voice like Trey Songz [a singer and rapper] \#nohomo.

Ro There seems to be an indent before this line that should not be there. bson: Jamey Johnson [a country music artist] is such an underrated artist. Dude could sing me to sleep every night \#nohomo.

Oz: Drew Dawson has a good voice. \#nohomo but solid [good] 'I'm yours' cover.

John: Ed Sheeran [a popular singer] and Michael Buble [a popular singer] have the most beautiful voices \#nohomo.

The singers mentioned in these tweets range from the normatively masculine Drew Dawson or Trey Songz to singers associated with more emotional, feminine love songs such as Ed Sheeran and Michael Buble.

Sometimes the phrase accompanies tweet content that explicitly frames this affection as romantic or sexual:

Willis: I would go gay for Scott Disick [the husband of celebrity Kourtney Kardashian] (emoji of woman holding one arm up in the air) \#nohomo.

A There seems to be an indent at the beginning of this line that should not be there. 1: For the record James Dean [American movie star] was sexy af \#nohomo.

Arwin: Eminem, Drake, Kanye West [popular rap artists] \#mancrush \#nohomo.

Sometimes these expressions of admiration are simple compliments, such as "Drew Dawson has a good voice" while others are more explicitly intimate such as "For the record James Dean was sexy af [as fuck]."

Sports As with celebrities, tweeters deployed the phrase "no homo" in conjunction with tweeting about admiration or affection for players or particular sports ( $n=27 ; 17.8 \%$ of all instances of Liking Things).

Hector: My love for Kobe Bryant [professional basketball player] tho....\#NoHomo." 
$\operatorname{Tr}$ There seems to be an indent at the beginning of this line that should not be there. ent: I $<3$ Van Gaal [former Dutch football player] \#nohomo.

Kyan: I can't believe I'm saying this but I seriously can't wait for soccer season \#nohomo

Shane: I had a dream I met the full BvB [German football team, Borussia Dortmund] team I cried when I saw Marco Reus [German football player]. \#nohomo

Cy: My idol@jeffreychristi3's new Ceres [Filipino football team] jersey is so cool! Looking good! But still sad you had to leave Global [Filipino football team]. : (\#BitterSweetMoment \#NoHomo.)

The athletes and sports that tweeters express admiration for represent a wide range of sports-soccer, football and basketball, for instance. As with celebrities, the gender of the athletes or teams usually mirrors that of the tweeter (i.e., mostly male).

When used in a positive emotional context to accompany statements of liking things, "no homo" accompanies a range of content about activities, interests, and tastes. Sometimes these tweets involve sexual meanings such as when Jay jokes, "get a room," in response to Ergo's compliment of another tweeter's picture. However, other times the content has little to do with sexuality such as when Kyan writes that he "can't wait for soccer season." In other words, "no homo" is used in a wide range of positive tweets about "liking things," not just those tweets with sexual content.

\section{Friendship}

When used in the expression of positive emotions, the phrase "no homo" was found in tweets containing expressions of friendship $(n=168 ; 49.1 \%$ of all instances of Positive Emotional usage). "No homo" accompanies two main forms of tweet content centered on friendship: tweets that are a part of the "everyday work" of friendship ( $n=58 ; 34.5 \%$ of all instances of Friendship) and tweets that express what we call "deep affection" ( $n=110 ; 65.5 \%$ of all instances of Friendship) between friends.

Everyday Work "No homo" appears in tweets doing the daily work of friendship. These tweets involve content such as friends casually writing greetings to one 
another, requesting another's contact information or joking around about hanging out, as exemplified by the following tweets:

Frankie: just DM [send a direct or private message] me ur [your] number bro I lost ur \# [your number]. Nohomo.

$\mathrm{J}$ There seems to be an indent at the beginning of this line that should not be there. orge: Tonight was literally all about Brad. I need to find uglier friends so I can get the attention (cry-laugh emoji) nohomo.

Landon: \#fundaysunday \#bromance \#nohomo \#okaymaybealittle.

In these tweets, "no homo" accompanies the everyday moments of friendship, losing someone's number and reflecting on hanging out with friends for instance. Landon even perhaps plays a bit with the affection he feels for his friends as he comments on "Funday Sunday" suggesting he "may be a little" gay in his final hashtag: \#okaymaybealittle.

More specifically, "no homo" may be deployed when male friends make plans to "hang out" [get together socially].

Chad: So I guess the plan is to get off work in an hour and then head back over to a tack auction [a sale of horse related items] then having man time at Hooters [a restaurant featuring scantily clad female servers] (followed by an "okay" symbol). Nicole: I'm sorry but the "man time" cracks me up (three "okay" symbols). Chad: \#nohomo \#nobrokeback [a reference to the movie Brokeback Mountain about two cowboys who fall in love]. Nicole: I wasn't even thinking like that I mean you are going to hooters and all (laugh cry emoticon).

Chad is making plans with a friend to hang out at an explicitly heterosexual venue known for its large chested and scantily clad waitresses and deploys "no homo" to frame his time with his male friend.

Some tweeters make jokes about the content of their time together when they tweet about it. For instance, one poster shares photos of himself and a friend in the front seat of a car wearing sunglasses:

Sam: Me and Al $>>>>$ Tan-bear and Darbs [the $>>>$ symbols mean more than or better than]. Darbs: Damn man, always outdoing me and Tan-bear by a long shot (sad face emoji). Sam: It was a close 
call...We got the edge because we're rocking girl shades (smiling emoji with sunglasses) \#NoHomo.

Sam designated the sunglasses he and his friends wear as "girl shades," suggesting that they are wearing girls' sunglasses, perhaps a form of gender transgression. This gender transgression is framed as allowing them to "out do" their friends Darbs and Tan-bear.

We see similar behavior when tweeters post about what they are doing with their friends when that behavior involves touching one another:

Bert: If we cuddle you get to sleep on my soft ass bed. Milt: The homie bed is soft though \#nohomo.

E There seems to be an indent at the beginning of this line that should not be there. ric: Anyone seeing two guys riding through Lancaster on a moped it's @carneyworld and I \#dick2ass \#no homo.

Doug: That was the best hug ever \#bromo \#nohomo.

The phrase "no homo" is used in a variety of ways to express accompany tweets about friendship. Tweeters use it to accompany tweets about hanging out, making plans with or the content of their actual hang-out time, sometimes making joke about behaviors that might be understood as gay such as same-sex touching or wearing items associated with girls.

Deep Affection More commonly ( $n=110 ; 65 . \%$ of all instances of Friendship) "no homo" is used in expressions of what we call "deep affection" in which tweeters write about their attachment to one another. These tweets usually express feelings about missing a friend, looking forward to seeing a friend or loving a friend. "No homo" is used in conjunction with tweeters' expressions of missing their friends, as in the following tweets:

Steve: Haha it's a small world! Might see that boy Chase again. Chase: You'll see me son! I've been missing hanging out with you \#nohomo

T There seems to be an indent at the beginning of this line that should not be there. yler: Just about to live my life and not worry about anything (smiling emoji with a heart). Zach: Action speaks louder than works. Young Grasshopper. Tyler: Yeah I know (semi-smile 
emoji). Zach: Don't speak about it be about it. Tyler: You need to move back. I actually miss you. \#nohomo.

Colin: I miss you \#nohomo.

Tweeters also use "no homo" to accompany expressions of devotion to and love for one another:

Matt: love you man. Mike: \#nohomo. Matt: never. Miss you too. We gotta get up (broken heart emoji). Mike: When are you off next what's good for tomorrow night I gotta lotto tell you lol [laughing out loud].

$\mathrm{G}$ There seems to be an indent at the beginning of this line that should not be there. ene: Really appreciate this dude (Brad) man not too many dudes can say they have Solid bros but god bless me with 1 love you bro nohomo

Jax: I just want the simple things. Max: Like get that volume at an even number (okay sign)... Life doesn't get much better than that. Jax: LMAO if only every girl knew me as well as you man \#nohomo.

Zack: @ocinorian \#besties \#friendsforlife \#cuddlebuddies \#brolove \#bros \#bromance \#nohomo.

The phrase "no homo" accompanies these expressions as primarily male tweeters tell each other they love each other, convey that they miss each other, and they even comment on how much better they know each other than women do. They expressly reflect on and talk about their friendships with one another through the use of the phrase "no homo."

\section{Discussion}

The present study of tweets containing the phrase "no homo" indicates that the phrase is a gendered one used primarily in conjunction with the expression of positive sentiments. The phrase "no homo" is used predominantly in tweets by men. A minority of tweet instances in our study expresses negative sentiments. Tweets that contain the phrase "no homo" in a negative context focus on condemning or distancing oneself from homosexuality or gender transgression. The modal use of 
the phrase "no homo" in the tweets under study was in a tweet expressing a positive emotional sentiment in which tweeters convey that they like something or express affection for a friend.

The apparently contradictory use of a homophobic phrase to express positive emotions seems at first to be a puzzle. However, based on the findings we presented, we suggest three main lines of analysis regarding this particular case of homophobic language. First, the phrase "no homo" functions as a linguistic inoculation against possible accusations of homosexuality. Second, the phrase "no homo" performs a dual containing and enabling function, drawing a boundary that allows those who tweet it to both express a positive sentiment about a topic that might be considered unmasculine, while at the same time conveying the message that this topic is indeed unmasculine. Third, the use of the phrase "no homo" on Twitter indicates the limited role of pleasure in enactments of normative masculinity.

\section{Inoculating}

The relatively rare expression of negative sentiments with the phrase "no homo" supports Berggren's (2012) interpretation of the phrase as a "straight inoculation." The expression of negative sentiments in our study addresses gender transgression, same-sex sexuality or gay identity. When Dusty, for instance, says that hip-hop artist Nas is "gay AF" he follows this up with a tweet reading "I said NOHOMO, so this cant be used against me." Mentioning someone's sexual identity perhaps renders one vulnerable to accusations of homosexuality, a charge presumably against which "no homo" can inoculate.

Similarly, even when condemning a (presumable) man's gender transgression for identifying as a woman, two tweeters accompany their condemnatory tweets with "no homo" as if addressing the fact that they believe there is a mismatch between the what they think the poster's gender identity is and what the post claims it is might call their own sexuality into question. Whereas other homophobic epithets perform a labeling function (stigmatizing another as gay), "no homo" performs a negating function because it is deployed to prevent being the recipient of a stigmatizing label. This is perhaps how we would expect "no homo" to be used-to renounce same-sex behavior and inoculate oneself against it.

\section{Drawing Boundaries}


The deployment of the phrase "no homo" both allows for the expression of positive sentiments, while at the same time containing those sentiments such that they do not render the tweeter vulnerable to accusations of gender transgression, effeminacy or same-sex desire. In this sense, the phrase "no homo" facilitates a particularly masculinized construction of positive emotional expression by enabling men to express seemingly platonic affection toward one another, while at the same time ensuring that such intimacy is understood as non-sexual and rendering it normatively masculine.

"No homo" cements the bonds of friendship and it renders the intimacy between friends nonsexual. In these tweets men flirt with same-sex intimacy and back away from it quickly, with the deployment of a "no homo." "No homo" thus carves out a space to express friendship and emotional connection. It also contains that space by framing it as explicitly non-sexual. Some tweeters joke about being gay, and in doing so use the phrase to make clear their relationship is a non-sexual friendship.

Deploying "no homo" to contextualize intimacy expressed through same-sex touching perhaps mitigates against the risk of the "fag discourse" often deployed in such instances (Pascoe 2011). "No homo" performs an interesting functioncarving out a space for same-sex touching while guarding against homophobic epithets. As such, "no homo" both enables and contains forms of same-sex intimacy in friendships. The use of "no homo" creates space for this expression, but also affirms such behavior as fundamentally unmasculine. In this sense, "no homo" is deployed when ambiguity about same-sex friendships may occur in order to indicate that the tweeter remains on the non-taboo side of a social boundary, while simultaneously marking that boundary and making it visible.

Additionally, the phrase "no homo" actively constructs the taboo content around which a social boundary must be drawn. That is the sentiments or behaviors it accompanies are not always obviously unmasculine. For instance, the phrase is deployed alongside expressions of liking things that are seemingly gender neutral, such as tea or sunsets, or even presumably masculine such as playing soccer. When used this way, the phrase itself has the effect of marking the topic of the tweet itself as unmasculine. Behaviors like liking sunsets, or cuddling with a girl while drinking tea are labeled unmasculine by the very use of the phrase "no homo." In this sense, it is not just that the phrase delineates a boundary, it also defines the sort of behavior and sentiment against which a boundary can be drawn.

\section{Expressing Pleasure}


As such, perhaps it is not liking Ed Sheeran, the singer of popular love songs mentioned by John as having a beautiful voice, or enjoying a romantic comedy like The Notebook that seems to be the issue; rather, what all of these examples have in common are the feelings that they bring out in individuals. When examining the positive emotional tweets as a whole, it seems that the overall function of "no homo" is to render expressions of pleasure unmasculine, while simultaneously allowing the expression of this pleasure. Indeed, the story of this homophobic epithet is, perhaps, ironically, one of the expression of pleasure-pleasure of friendships and connection with others, the joy in particular experiences, admiration for things or people, and affection for others.

As other scholars have noted, the constraint of certain forms of pleasure is central to constructions of contemporary masculinities (Bordo 2000). These uses of the phrase "no homo" illustrate the process of carving out spaces for pleasure to be expressed, while simultaneously doing the performative work that one needs to maintain a claim on normative masculinity. In this sense, "no homo" constitutes a ritualized form of stigma management, ensuring that one's identity is not feminized through these expressions. The use of "no homo" allows for both a discursive containment of pleasure and a masculinization of that pleasure.

Looking at how "no homo" is used to express pleasure reveals a bit of what Barrie Thorne calls "gender play" (Thorne 1993; Thorne and Luria 1986) because tweeters simultaneously reinforce and subvert particular gendered norms. "No homo," as a phrase, reinforces gendered norms about detachment and un-emotionality, and at the same time creates space to express positive emotions. As such "no homo" both regulates expressions of pleasure and provides room for them.

The tweets and conversations expressing pleasure in liking things or caring for friends are examples of what Connell (1987, p. 99) calls "the structure of cathexis" or patterns of emotional attachment through which gender inequalities are forged. Emotional relations are ordered to sustain gender inequality; as such, "no homo" does the work of slightly altering such relations while not actually challenging them. In doing so, the deployment of the phrase "no homo" might function as an example of what Bridges and Pascoe (2014) call "hybrid masculinity." Hybrid masculinities work to fortify existing social and symbolic boundaries in ways that often work to conceal systems of power and inequality in historically new ways. The deployment of "no homo" reifies particular meanings of masculinity (as unemotional, unattached, rational, for instance) while simultaneously creating space for the expression of these sentiments. 


\section{Limitations and Future Research}

Our findings indicate several trajectories for future research. First, they suggest that this sort of qualitative research might complement findings of "big data" focused on sentiment analysis by showing why and how particular sentiments are expressed (Pang and Lee 2008). Analyzing language in these online spaces can help to reveal what is not so easily measured in "big data" approaches: the complex social meanings that are deployed when one levies particular sexualized insults. Second, our findings suggest that future research continue the project of refining and clarifying definitions and measurements of homophobia as well as attend to the varied ways homophobic language functions in interaction. Finally, survey research on the meanings of various homophobic epithets (along the lines of Brown and Alderson 2010) is needed to build a more sophisticated analysis of how we know what we know about homophobia.

The present study is limited by various components. First, because we did not speak to those using the phrase "no homo" in their tweets, no claims can be made about the intent of those who used this language. Second, the ability to make claims about tweeters' race and gender is limited to the authors' identification, which may not align with the tweeters' self-identifications. Third, the representativeness of the findings in the present article are limited by the small sample size. Fourth, our study cannot address the content of tweets that are not publicly available or those written in languages that are not English.

\section{Practice Implications}

These findings have multiple implications for practitioners. Research in therapeutic settings suggest that gendered homophobia is a structuring force for young men and boys (Corbett 2001). Research on boys' and young men's friendships suggest that homophobia is a central component to these friendship as well (Way 2012). This research adds to what we know about how homophobia shapes the lives of boys and young men and their friendships. These findings complicate what we know about how homophobic epithets work, highlighting how this particular epithet accompanies the expression of positive emotions about pleasure and, importantly, intimate expressions of friendship. Those who work with youth in educational, therapeutic, and other settings may be cautioned not to understand all seemingly homophobic expressions solely as anti-gay language, but also as, perhaps, an attempt to express sentiments young men and boys understand as incompatible with normative masculinity. This sort of understanding suggests that a discussion-based response to anti-gay language may be more productive than a punitive one. These 
young men may be managing particular expectations of masculinity in these expressions rather than simply expressing disapproval for gays, lesbians or men regarded as insufficiently masculine.

\section{Conclusion}

Our research suggests we are continuing to witness homophobia's "ebb and flow" (Plummer 2014). Perhaps the mercurial state of findings measuring, explaining, and defining homophobia have in part to do with a lack of consensus as to what we actually mean when we call language, behavior or feelings homophobic. Our case study of the phrase "no homo" in an online environment suggests that the work that homophobic language does is complicated. In the case of "no homo" it protects the speaker against accusations of homosexuality; it delineates boundaries between masculine and unmasculine behavior, topics, and sentiments; and it enables the expression of pleasurable emotions about varied topics and, perhaps most importantly, between friends.

Homophobic language, especially when humorous, can "tell us about culturally held stereotypes and a society's collective anxieties" (Nardi and Stoller 2008, p. 389) as well as "about how sexuality and gender are constructed in a particular time and place" (Nardi and Stoller 2008, p. 389). An examination of the phrase "no homo" suggests that current cultural anxieties focus on the way in which contemporary masculinity is not supposed to entail expressing desire, pleasure, connection or friendly affection and that this phrase, perhaps ironically, carves out a space for the expression of these sentiments. As such, the young men who deploy it may be attempting to transgress expectations of normative masculinity while, perhaps unintentionally, reinforcing these same expectations.

\section{Acknowledgements}

$\mathrm{AQ} 2$

The authors thank the Earl and Edna Stice Memorial Lectureship in Social Sciences Fund and the David M. and Nancy L. Petrone Faculty Scholar Fund for supporting this research. We also thank Aaron Gullickson and Annie McGlynn-Wright for their help with the quantitative aspects of our article; as well as audiences at the University of Washington, Boston University, and University of Chicago for their feedback on various versions of our article. Finally, we thank Andrea Herrera for her research assistance on our project.

Compliance with Ethical Standards $\mathrm{AQ3}$ 
Conflict of interest Neither author has potential conflicts of interest regarding this research.

Research involving Human Participants and/or Animals No animals were involved in this research. The University of Oregon Institutional Review Board determined that this project did not need to undergo review as it dealt with publicly available online textual data. I can provide documentation of this decision.

Informed Consent No informed consent was necessary for this project.

\section{References}

Allison, K. R., \& Bussey, K. (2016). Cyber-bystanding in context: A review of the literature on witnesses' responses to cyberbullying. Children and Youth Services Review, 65, 183-194. https://doi.org/10.1016/j.childyouth.2016.03.026 .

Altemeyer, B. (1988). Enemies of freedom: Understanding right-wing authoritarianism (Vol. xxix). San Francisco, CA: Jossey-Bass.

Altemeyer, B. (2001). Changes in attitudes toward homosexuals. Journal of Homosexuality, 42(2), 63-75. https://doi.org/10.1300/J082v42n02_04 .

Anderson, M., Perrin, A., \& Jiang, J. (2018). 11\% of Americans don't use the internet. Who are they? Washington, D.C.: Pew Research Center. Retrieved from http://www.pewresearch.org/fact-tank/2018/03/05/some-americans-dont-use-theinternet-who-are-they/ .

Berggren, K. (2012). "No homo": Straight inoculations and the queering of masculinity in Swedish hip hop. NORMA, 7(1), 51-66.

Bordo, S. (2000). The male body: A new look at men in public and in private (1st ed.). New York: Farrar, Straus and Giroux.

Bridges, T., \& Pascoe, C. J. (2014). Hybrid masculinities: New directions in the sociology of men and masculinities. Sociology Compass, 8(3), 246-258. https://doi.org/10.1111/soc4.12134.

Brown, J. R. (2011). No homo. Journal of Homosexuality, 58(3), 299-314. https://doi.org/10.1080/00918369.2011.546721 . 
Brown, T. L., \& Alderson, K. G. (2010). Sexual identity and heterosexual male students' usage of homosexual insults: An exploratory study. The Canadian Journal of Human Sexuality, 19(1/2), 27-42.

Bryant, K., \& Vidal-Ortiz, S. (2008). Introduction: Retheorizing homophobias. Sexualities, 11(4), 387-396. https://doi.org/10.1177/1363460708091740 .

Charmaz, K. (2014). Constructing grounded theory (2nd ed.). Los Angeles: Sage.

Connell, R. (1987). Gender \& power: Society, the person, and sexual politics. Redwood City: Stanford University Press.

Connell, R. (2005). Masculinities (2nd ed.). Berkeley: University of California Press.

Corbett, K. (2001). Faggot=loser. Studies in Gender and Sexuality, 2(1), 3-28. https://doi.org/10.1080/15240650209349168 .

Costa, A. B., Bandeira, D. R., \& Nardi, H. C. (2013). Systematic review of instruments measuring homophobia and related constructs. Journal of Applied Social Psychology, 43(6), 1324-1332. https://doi.org/10.1111/jasp.12140 .

Doan, L., Loehr, A., \& Miller, L. R. (2014). Formal rights and informal privileges for same-sex couples: Evidence from a national survey experiment. American Sociological Review, 79(6), 1172-1195.

Duggan, M. (2015). Mobile messaging and social media - 2015. Washington, D.C.: Pew Research Center. Retrieved from:

http://www.pewinternet.org/2015/08/19/mobile-messaging-and-social-media$2015 /$.

Erdur-Baker, Ö. (2010). Cyberbulling and its correlation to traditional bullying, gender and frequent and risky usage of internet-mediated communication tools. New Media \& Society, 12(1), 109-125. https://doi.org/10.1177/1461444809341260 .

Ey, L.-A., Taddeo, C., \& Spears, B. (2015). Cyberbullying and primary-school aged children: The psychological literature and the challenge for sociology. 
Societies, 5(2), 492-514. https://doi.org/10.3390/soc5020492 .

Ezzell, M. B. (2009). "Barbie Dolls" on the pitch: Identity work, defensive othering, and inequality in women's rugby. Social Problems, 56(1), 111-131. https://doi.org/10.1525/sp.2009.56.1.111.

Herek, G. M. (2004). Beyond "homophobia": Thinking about sexual prejudice and stigma in the twenty-first century. Sexuality Research \& Social Policy, 1(2), 6-24. https://doi.org/10.1525/srsp.2004.1.2.6 .

Herek, G. M. (2007). Confronting sexual stigma and prejudice: Theory and practice. Journal of Social Issues, 63(4), 905-925. https://doi.org/10.1111/j.1540-4560.2007.00544.x .

Herek, G. M. (2015). Beyond "homophobia": Thinking more clearly about stigma, prejudice, and sexual orientation. American Journal of Orthopsychiatry, 85(5), S29-S37. https://doi.org/10.1037/ort0000092 .

Herek, G. M., \& McLemore, K. A. (2013). Sexual prejudice. Annual Review of Psychology, 64(1), 309-333. https://doi.org/10.1146/annurev-psych-113011143826 .

Ikard, D. (2013). Boys to men: Getting personal about black manhood, sexuality, and empowerment. Palimpsest: A Journal on Women, Gender, and the Black International, 2(1), 59-73.

Jain, B. B. \& Nielsen, R.C. (2016, May 16). A look at the gender distribution of tweets about global development [Blog post]. Retrieved from: https://www.unglobalpulse.org/news/look-gender-distribution-post-2015-relatedtwitter-discussions .

Kehily, M. J., \& Nayak, A. (1997). "Lads and laughter": Humour and the production of heterosexual hierarchies. Gender and Education, 9(1), 69-87.

Kehler, M. D. (2007). Hallway fears and high school friendships: The complications of young men (re)negotiating heterosexualized identities. Discourse: Studies in the Cultural Politics of Education, 28(2), 259-277. https://doi.org/10.1080/01596300701289375. 
Kimmel, M. (1994). Masculinity as homophobia: Fear, shame and silence in the construction of gender identity. In S. Whitehead \& F. Barrett (Eds.), The masculinities reader (pp. 266-287). Thousand Oaks: Sage.

Kimmel, M., \& Mahler, M. (2003). Adolescent masculinity, homophobia, and violence random school shootings, 1982-2001. American Behavioral Scientist, 46(10), 1439-1458. https://doi.org/10.1177/0002764203046010010 .

Koh, Y. (2014, January 21). Twitter users' diversity becomes an ad selling point. Wall Street Journal. Retrieved from http://www.wsj.com/articles/SB10001424052702304419104579323442346646168

Kowalski, R. M., \& Limber, S. P. (2008). Electronic bullying among middle school students. Journal of Adolescent Health, 41(6), S22-S30. https://doi.org/10.1016/j.jadohealth.2007.08.017 .

Kowalski, R. M., Giumetti, G. W., Schroeder, A. N., \& Lattanner, M. R. (2014). Bullying in the digital age: A critical review and meta-analysis of cyberbullying research among youth. Psychological Bulletin, 140(4), 1073-1137. https://doi.org/10.1037/a0035618 .

Lance, L. (2008). Social inequality on the college campus: A consideration of homosexuality. College Student Journal, 42(3), 789-794.

Lazer, D., \& Radford, J. (2017). Data ex machina: Introduction to big data. Annual Review of Sociology, 43, 19-39. https://doi.org/10.1146/annurev-soc060116-053457.

Lehne, G. (1998). Defining the male role. In M. Kimmel \& M. Messner (Eds.), Men's lives (pp. 237-249). Boston: Allyn and Bacon.

Levy, N., Cortesi, S., Gasser, U., Crowley, E., Beaton, M., Casey, J., ... Nolan, C. (2012). Bullying in a networked era: A literature review. Berkman Klein Center for Internet \& Society at Harvard University. Retrieved from https://cyber.harvard.edu/publications/2012/kbw_bulling_in_a_networked_era .

Loftus, J. (2001). America's liberalization in attitudes toward homosexuality, 1973 to 1998. American Sociological Review, 66(5), 762-782. 
https://doi.org/10.2307/3088957 .

Loker, K. (2012, October 16). 5 stats on who makes "the twitter narrative" (and/or who's on and uses twitter). Adweek. Retrieved from http://www.adweek.com/digital/twitter-narrative-makeup-demographics-studies/

Mayfield, W. (2001). The development of an internalized homonegativity inventory for gay men. Journal of Homosexuality, 41(2), 53-76. https://doi.org/10.1300/J082v41n02_04.

McCann, P. D., Plummer, D., \& Minichiello, V. (2010). Being the butt of the joke: Homophobic humour, male identity, and its connection to emotional and physical violence for men. Health Sociology Review, 19(4), 505-521. https://doi.org/10.5172/hesr.2010.19.4.505.

McCormack, M., \& Anderson, E. (2014). The influence of declining homophobia on men's gender in the United States: An argument for the study of homohysteria. Sex Roles, 71(3-4), 109-120. https://doi.org/10.1007/s11199-0140358-8 .

Meyer, D. (2012). An intersectional analysis of lesbian, gay, bisexual, and transgender (LGBT) people's evaluations of anti-queer violence. Gender \& Society, 26(6), 849-873. https://doi.org/10.1177/0891243212461299 .

Mislove, A., Lehmann, S., Ahn, Y. Y., Onella, J. P., \& Niels Rosenquiest, J. (2011). Understanding the demographics of twitter users. Barcelona: Paper presented at Fifth International Association for the Advancement of Artificial Intelligence Conference on Weblogs and Social Media.

Nardi, P. M., \& Stoller, N. E. (2008). "Fruits", "fags", and "dykes": The portrayal of gay/lesbian identity in "nance" jokes of the 50s and 60s. Journal of Homosexuality, 55(3), 388-410. https://doi.org/10.1080/00918360802345107 .

Omnicore. (2018). Twitter by the numbers: Stats, demographics \& fun facts. Retrieved from https://www.omnicoreagency.com/twitter-statistics/ .

Pang, B., \& Lee, L. (2008). Opinion mining and sentiment analysis. Foundations and Trends in Information Retrieval, 2(1-2), 1-135. 
https://doi.org/10.1561/1500000011 .

Pascoe, C. J. (2003). Multiple masculinities? Teenage boys talk about jocks and gender. American Behavioral Scientist, 46(10), 1423-1438.

https://doi.org/10.1177/0002764203251483 .

Pascoe, C. J. (2011). Dude, you're a fag: Masculinity and sexuality in high school (2nd ed.). Berkeley, CA: University of California Press.

Pew Research Center. (2003). Republicans unified, Democrats split on gay marriage. Washington, D.C. Retrieved from: http://assets.pewresearch.org/wpcontent/uploads/sites/5/legacy-pdf/197.pdf .

Pew Research Center. (2016). Changing attitudes on gay marriage. Washington D.C. Retrieved from http://www.pewforum.org/fact-sheet/changing-attitudes-ongay-marriage/ .

Plummer, D. (2014). The ebb and flow of homophobia: A gender taboo theory. Sex Roles, 71(3-4), 126-136. https://doi.org/10.1007/s11199-014-0390-8 .

Poteat, V. P., Kimmel, M. S., \& Wilchins, R. (2011). The moderating effects of support for violence beliefs on masculine norms, aggression, and homophobic behavior during adolescence. Journal of Research on Adolescence, 21(2), 434447. https://doi.org/10.1111/j.1532-7795.2010.00682.x .

Roach, T. (2015). Becoming fungible: Queer intimacies in social media. Qui Parle: Critical Humanities and Social Sciences, 23(2), 55-87. https://doi.org/10.5250/quiparle.23.2.0055 .

Schrock, D., \& Schwalbe, M. (2009). Men, masculinity, and manhood acts. Annual Review of Sociology, 35, 277-295.

Sears, J. T., \& Williams, W. L. (1997). Overcoming heterosexism and homophobia: Strategies that work. New York: Columbia University Press.

Shapp, A. (2015). Gender variation in the pragmatic use of twitter hashtags. Paper presented at The Annual Meeting of the Linguistic Society of America, Portland. 
Smith, A., \& Anderson, M. (2018). Social media use in 2018. Washington, D.C.: Pew Research Center. Retrieved from http://www.pewinternet.org/2018/03/01/social-media-use-in-2018/ .

Thorne, B. (1993). Gender play: Girls and boys in school. New Brunswick, NJ: Rutgers University Press.

Thorne, B., \& Luria, Z. (1986). Sexuality and gender in children's daily worlds. Social Problems, 33(3), 176-190. https://doi.org/10.2307/800703 .

Thurlow, C. (2001). Naming the "outsider within": Homophobic pejoratives and the verbal abuse of lesbian, gay and bisexual high-school pupils. Journal of Adolescence, 24(1), 25-38. https://doi.org/10.1006/jado.2000.0371 .

Way, N. (2012). Close friendships among adolescent boys. Thymos, 6(1/2), 116136.

Zych, I., Ortega-Ruiz, R., \& Del Rey, R. (2015). Scientific research on bullying and cyberbullying: Where have we been and where are we going. Aggression and Violent Behavior, 24, 188-198. https://doi.org/10.1016/j.avb.2015.05.015 . 